\title{
M2CIM-DSS: A Model for Measuring Continuance Intention in Decision Support Systems
}

\author{
Ali Hussein Mohammed ${ }^{1}$, Ayad Hameed Mousa ${ }^{2}$, Nawal Mousa Almeyali ${ }^{3}$, Intedhar Shakir Nasir \\ ${ }^{1}$ Directorate general of education in Karbala province, Iraq \\ ${ }^{2}$ College of Computer Science and Information Technology, University of Kerbala, Iraq \\ ${ }^{3,4}$ College of Medicine, University of Kerbala, Iraq
}

\begin{tabular}{l}
\hline \hline Article Info \\
\hline Article history: \\
Received Feb 23, 2021 \\
Revised Jul 21, 2021 \\
Accepted Aug 14, 2021 \\
\hline
\end{tabular}

\section{Keywords:}

Decision Support System, Technology Organization Environment Framework, Technology acceptance model, Expectation-confirmation model, and Structural Equation Models.

\begin{abstract}
Currently, the core trend of Higher Education Institutes (HEI) to invest in decision support systems (DSS) to improve their decision-making process. Due to technology emergence, HEI has been experiencing noteworthy changes. Many techniques such as DSS been adopted developed and implemented to support the educational process. Even though DSS has adopted and invested mainly in most sectors, a lack of research in investigating confirmed, the influencing factors on the intention of stakeholders to continue to use them. Consequently, the purpose of the study is to examine postadoption users' satisfaction and users' intention to continue using DSS. This study combining two theoretical models, the Technology Acceptance Model, and The Technology Organization Environment Framework, to examine users' intentions to continue using DSS. The data collection process has conducted using 240 respondents, who belong to HEI institutions (Academia and management staff), who work on DSS. Structural Equation Modeling was utilized to analyze structural relationships among the proposed model's factors. The authors used several methods such as hierarchical regression, oneway ANOVA, descriptive statistics, as well as t-test have applied to evaluate the model's components' relevancy, understanding, and pertinence to each other. The result shows the proposed model fits the data and had a good explanation than the existing models. On the other hand, the results show the importance of equipping DSS with real-time support because they have positive repercussions in the decision-making process The implications as well as the limitations of this study have been extensively discussed.
\end{abstract}

Copyright () 2021 Institute of Advanced Engineering and Science. All rights reserved.

\footnotetext{
Corresponding Author:

Ayad Hameed Mousa,

Department Computer Science,

College of Computer Science and Information Technology,

123 Hilla Road, Frehaha, University Of Kerbala, Karbala, Iraq. ayad.h@uokerbla.edu.iq
}

\section{INTRODUCTION}

Due to technology emergence, HEI has been experiencing noteworthy changes. Many techniques such as DSS have been adopted developed and implemented to support and enhance the educational process. Most of the previous studies have focused on elementary uses in terms of measuring the acceptance and adoption of new technology. DSS empowers HEIs to measure, monitor, and manage their performance efficiently and effectively. even though users' initial adoption and acceptance of technology are significant, however, the success of such technology is based on long-term continuous utilization [1].

Unconsidered use of IT can lead to time-consuming and unexpected costs as well [2]. Therefore, investigating the behavior of the users during and after the adoption of the technology, which leads either to the continuation of the use of the technology or the exclusion of that technology from accreditation considered one of the important matters for the application of that technology in the organization [3]. According to Gartner, 2020, Worldwide DSS spending is projected to total $\$ 3.8$ trillion in 2021, an increase of $4 \%$ from 2020 , according to the latest forecast by Gartner, Inc. DSS spending in 2020 is expected to total $\$ 3.6$ trillion, down $5.4 \%$ from 2019 . 
DSS is defined as being "a computerized program used to support determinations, judgments, and courses of action in an organization or a business. A DSS sifts through and analyzes massive amounts of data, compiling comprehensive information that can be used to solve problems and in decision-making" [4]. Administrations and decision-makers of (HEIs) are also experiencing huge and multidimensional information while interacting with students' data forces them to adopt and utilize DSS for long-term strategy.

Perceived usability represented by (perceived ease of use (PEU) and perceived usefulness (PU) ) has become the most critical factors affecting the adoption of DSS in organizations [5]. Perceived ease of use is "the degree to which a person believes that using a particular system would be free from effort" [6]. Distinguishing the determinants influencing DSS continuance intention is becoming a necessity for any organization as adopted by many organizations.

The Technology Acceptance Model (TAM) in conjunction with the Technology Organization Environment Framework (TOE) has generally applied in interpreting user-acceptance behavior and organization-acceptance behavior over a wide scope of adopting new technology such as DSS [7], such as business organization [8], telemedicine [9], intensive care units [10], to support the sustainability goals of Nike [11], enterprise resource planning [12], or small service enterprises with strong operations [13].

As mentioned early, previous studies were ordinarily concerned about pre-acceptance and adoption for technology and neglected unintentionally the post-acceptance to continue to utilize or refuse the intended technology [14-16]. Thus, a lack of studies confirms the determinants affecting customers to keep use technology after the organizations had accepted it. In light of those challenges, the TAM and the TOE were synthesized to propose a blended model for interpreting and foretelling customer's continued intent to use DSS.

Data collection was conducted using 240 respondents in the HEI institutions (Academia and management staff) who work on DSS. Structural equation modeling (SEM), for data analysis, the authors used several methods such as hierarchical regression, one-way ANOVA, descriptive statistics, as well as t-test were applied to assess the research model in terms of model's components relevancy, understanding, and pertinence to each other.

The organization of the rest of such paper will be as follows. Section 2 presents a review of relevant literature for DSS, the TAM model, and the TOE framework. The proposed model is outlined in section 3 as well as the relevant hypotheses were proposed and tested. Section 4 illustrates the research methodology followed in this study. Section 5 outlined the data collection and analysis. The obtained findings have been extensively discussed in Section 6. While section 7 outlines conclusions. The limitations have been highlighted in the final section of this study.

\section{THE TECHNOLOGY ACCEPTANCE MODEL (TAM)}

The Technology Acceptance Model (TAM) is an amplification of the Theory of Reasoned Action (TRA) [17] which was a theory initiated by [6] and since then has gone through sundry extensions and evolutions. The Technology Acceptance Model (TAM) is gaining popularity for understanding the relationship between humans and technology through its two factors "Perceived Usefulness (PU) and Perceived Ease of Use (PEU)". Both PU and PEU determine attitude towards use (ATT), which is defined as the user's acceptance of using the system. TAM is visualizing in Figure 1.

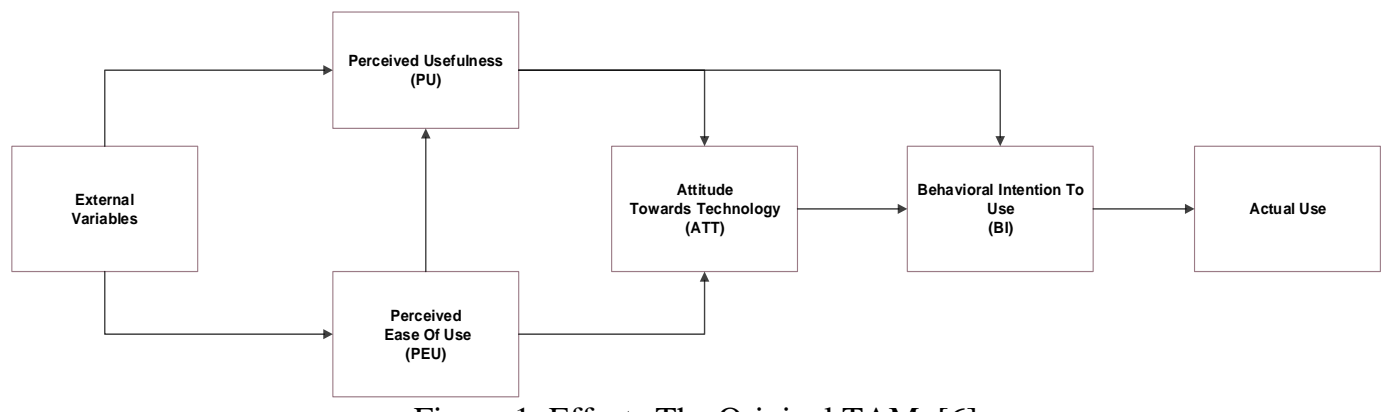

Figure 1. Effects The Original TAM [6]

As clearly shown from Figure 1, PEU directly affects PU. (ATT) and PU directly influences behavioral intention (BI). BI affects actual usage behavior.

\section{THE TECHNOLOGY ORGANIZATION ENVIRONMENT FRAMEWORK (TOE)}

TOE framework was proposed by [18]. It characterizes factors that affect technology adoption and its likelihood. TOE illustrates the process by which a corporation adopts and implements technological innovations is influenced by the technological context, the organizational context, and the environmental context [18], as shown in Figure 2. 


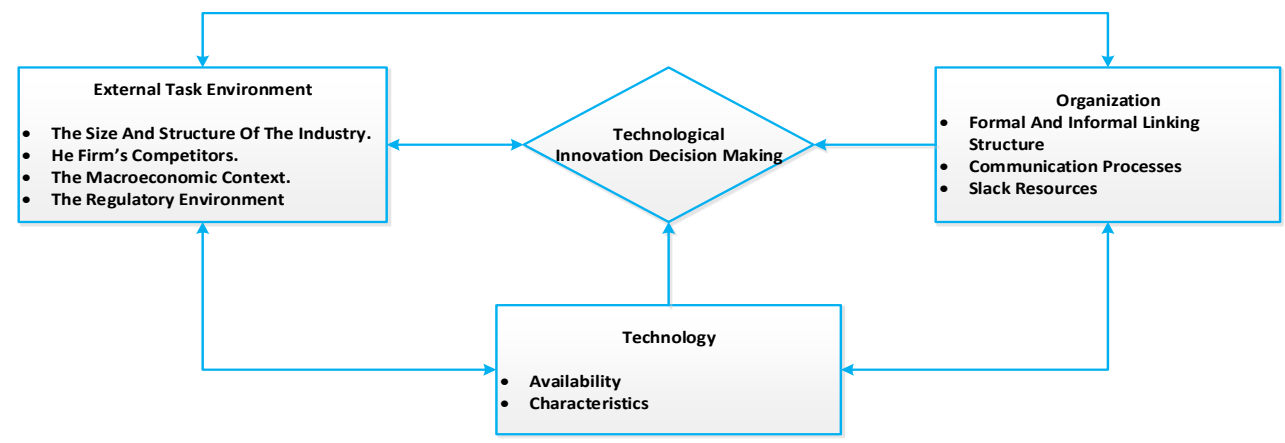

Figure 2. The Original TOE [18]

The technological context includes all technologies, whether internal or external, related to the organization. They might encompass both equipment and processes. The organizational context indicates the advantages and organizational resources of the firm, including the organization's size, degree of centralization, organizational structure, and human resources. While the environmental context part comprises the industry size, industry structure, and the regulatory environment. Besides, these three elements represent opportunities for measuring and accepting technology and innovations and thus affect the acceptance of technology from the institution's perspective.

\section{DECISION SUPPORT SYSTEM (DSS)}

At present, many organizations such as HEIs have already adopted and implemented DSS, and it is a significant investment business software for firms. Three essential ingredients need to build DSS software are the DSS database, the DSS model, and the DSS user interface. DSS currently, exists in most higher education institutions HEIs and most modern technologies and AI algorithms are used in the design and development of these systems to obtain intelligent systems used for analysis, performance measurement, monitoring, and business management for institutions, whether administrative or academic work.

\section{RESEARCH METHODOLOGY}

\subsection{Model Development and Hypotheses}

As mentioned above, this study combining two theoretical models, TAM, and TOE, and propose some factors that have influenced understanding the DSS continuance intention. Theoretically, the TAM and TOE have been confirmed to be useful models in facilitating to grasp and demonstrate user behavior in the adoption and utilization of a technology [6,18]. The proposed model developed for this study is based on TAM and TOE with some adaptations as shown in (Figure. 3). Within the TAM and TOE, performance expectancy is the degree to which the DSS user's individuals believe that continues using the DSS will assist them to improve their work performance.

Consequently, the proposed model consists of three external variables named "real-time decisionmaking (RT), Error control and help (ECH), and application behavior (AB) as well as the originally selected factors from TAM and TOE (Perceived Usefulness (PU), Perceived ease of use (PEU), and Technological Satisfactions (TS) Innovation Decision). Control of errors and assistance means that the decision support system must support the properties of the control in the event of errors and try to continue working despite the presence of errors as well as giving support and assistance to new users [19]. Application behavior means the behavior that the application behaves towards a specific event. Therefore, application behavior has a clear effect on whether or not the application is used continuously [20].

Since TOE and TAM focus on different portions of user perceptions of using technology, by utilizing those two models, the proposed model might deliver a general comprehension of continued DSS utilization. Current studies prove that the incorporation of several viewpoints can assist in a preferable understands of a certain technology [21-23].

Consequently, as shown in Figure 3, the proposed model will assist fill the gaps regards continuance acceptance of DSS in HEIs. Therefore, this study proposes the following hypotheses based on TAM and TOE models.

Hyp-1. Users' PU of DSS has a positive influence on their continued intention to use DSS.

Hyp-2. Users' PEU has a positive influence s positively related to their PU of DSS.

Hyp-3. Users' PEU has a positive influence on the users' continued intention to use DSS.

Hyp-4. Users' PU has a positive influence on their satisfaction with DSS.

Hyp-5. Users' PEU has a positive influence on their satisfaction with DSS.

Hyp-6. Users' TS with DSS has a positive influence on the continued intention to use DSS. 
Hyp-7. Users' ECH has a positive influence on their users' PU of DSS.

Hyp-8. Users' RT has a positive influence s positively related to their users' PU of DSS.

Hyp-9. Users' AB has a positive influence on their PEU of DSS.

Hyp-10. Users' RT has a positive influence on their satisfaction with DSS.

Note: Hyp. is an abbreviation of Hypothesis.

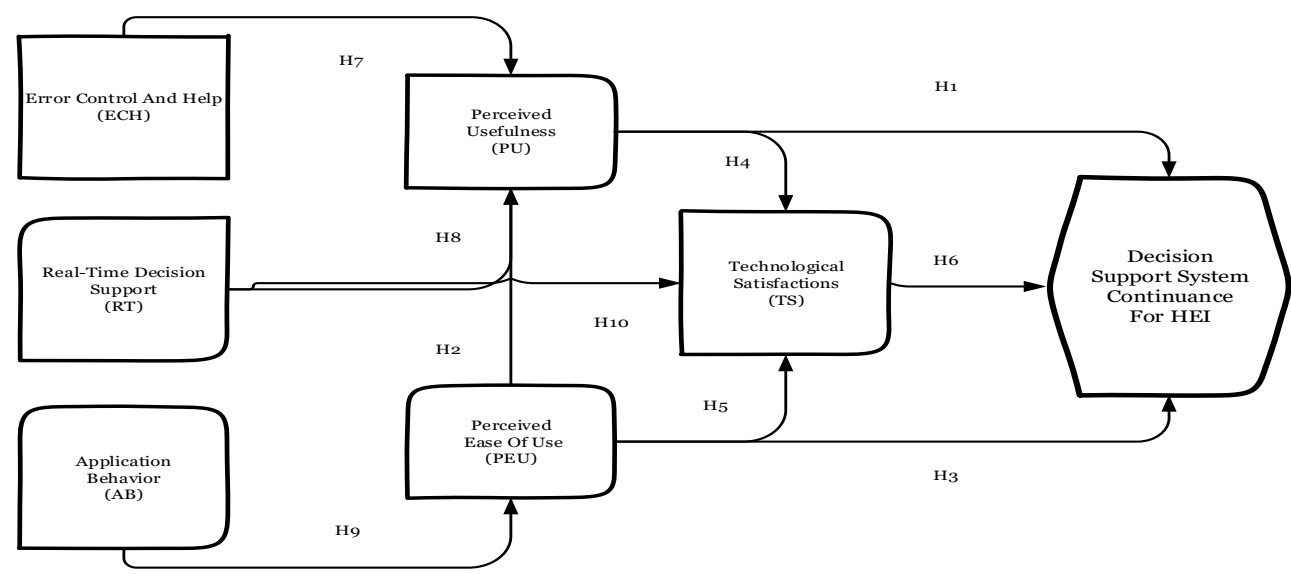

Figure 3. The Proposed Research Model

\subsection{Instrument Development and Procedure}

The main technique used to measure continuance intention is a 36-item questionnaire designed through the selection of items from current and relevant studies [24]. It is an exceedingly acceptable and helpful technique in data collecting procedures. The instrument has been adapted and validated through factor analysis and experts. All scale 35-items were paraphrased to link precisely to the context of DSS and measured using a 5-point Likert-type scale (from " $1=$ strongly disagree" to " 5 = strongly agree"). Besides, "somewhat agree on" was used in the middle category, because it forces the participants to choose a side, while neutral choice does not appropriate with the proposed model's variables of this study. To ensure the content validity of the instrument scales, validation tests have been conducted with nine educational experts and experience DSS actual users in Iraq. Furthermore, all of the selected items measuring the proposed model have been adopted from the relevant studies such as. Besides, to ensure the reliability of the data collected, a pilot study has conducted with 92 people who work as decision-makers staff or decision support systems staff from three universities. The number of respondents was determined based on the principal factor analysis sample size which is between 50 to 100 [25, 26]. Table 1 illustrated the development instrument.

Cronbach's alpha coefficient has been computed to ensure the reliability and consistency of the 35item scales utilized in the research. the obtained value of Cronbach's alpha for the model's elements was $>0.7$, confirming satisfactory reliability $[27,28]$.

Table 1. Instrument Dimensions, Items, and Relevant References

\begin{tabular}{llc}
\hline \multicolumn{1}{c}{ Dimensions } & \multicolumn{1}{c}{ No. Of Items } & References \\
\hline Perceived Usefulness (PU) & PU-item1...PU-Item6 & {$[8,21,29,30]$} \\
Perceived ease of use (PEU) & PEU-item7...PEU-Item12 & {$[8,21,29,30]$} \\
Real-time decision-making (RT) & RT-item13...RT-Item18 & {$[15,31-33]$} \\
Error control and help (ECH) & ECH-item19...ECH-Item24 & {$[15,34,35]$} \\
Application behavior (AB) & AB-item25...AB-Item30 & {$[14-16,36]$} \\
Technological Satisfactions (TS) & TS-item31...TS-Item36 & {$[37,38]$} \\
\hline
\end{tabular}

\subsection{Sampling}

The Selected sample within a population consisted of actual users of decision-support systems from various colleges from three universities. Consequently, 240 respondents belong to HEI institutions (academic and management staff) were participated in this study, as shown in Table 2.

To investigate the possible bias of failure to reply, The differences of the statistically significant in the answers of early (130 participants) versus late participants (110 participants) [39, 40] using gender, age, work experience, and level of study (educational level). The chi-square (X2) tests has conducted in matching the lasses among the groups confirmed no significant differences for gender $(X 2=3.878, p=0.041)$, work experience $(\mathrm{X} 2=1.777, \mathrm{p}=0.669)$, educational level $(\mathrm{X} 2=0.247, \mathrm{p}=0.719)$, and age $(\mathrm{X} 2=7.664, \mathrm{p}=0.542)$. Thus, it can be indicated that there is no significant failure to reply to the study. 
Table 2. The Demographic Data of Selected Sample

\begin{tabular}{|c|c|c|c|c|c|c|}
\hline \multicolumn{7}{|c|}{ The Basic Information } \\
\hline \multicolumn{2}{|c|}{ Gender } & \multicolumn{2}{|r|}{ Age } & \multicolumn{3}{|c|}{ Experience (Year) } \\
\hline Male & Female & $35-45$ & 46 and above & Less than 10 & 10 to 20 & More than 20 \\
\hline 159 & 81 & 135 & 105 & 40 & 120 & 80 \\
\hline \multicolumn{7}{|c|}{ The Position } \\
\hline \multicolumn{2}{|c|}{ Lower } & \multicolumn{2}{|r|}{ Middle } & \multicolumn{3}{|c|}{ Top Management } \\
\hline \multicolumn{2}{|c|}{62} & \multicolumn{2}{|r|}{99} & \multicolumn{3}{|c|}{79} \\
\hline
\end{tabular}

\subsection{Data Analysis}

As mentioned earlier, the SEM approach was utilized to test selected models as supported by [41] by two steps (1) test reliability and validity, and (2) examine the model fit findings. To test the reliability and validity the Confirmatory Factor Analysis (CFA) was utilized. In the second step, to examine the model fit findings, the structural models have been analyzed.

\section{THE OBTAINED FINDINGS}

As illustrated in Table 3, the proposed model has been examined within CFA, and the obtained findings were acceptable and fit. Moreover, to confirm the validity and reliability of the proposed model, the reliability, discriminant, and convergent validity have been examined. The Cronbach's alpha ranged from 0.773 to 0.854 while, the reliability ranged from 0.715 to 0.934 . These finding, however, indicates strong evidence of reliability as supported by [42]. Moreover, the obtained factor loading results for all items were significant and were more than 0.60 as recommended by [43]. As well, the same with Cronbach's Alpha value (measuring reliability) of all items which exceeded 0.7 as recommended by [44]. On the same aspect, the composite reliability value of all items, more than 0.75 which leads to statistical significance.

Table 3. Construct Reliability and Validity

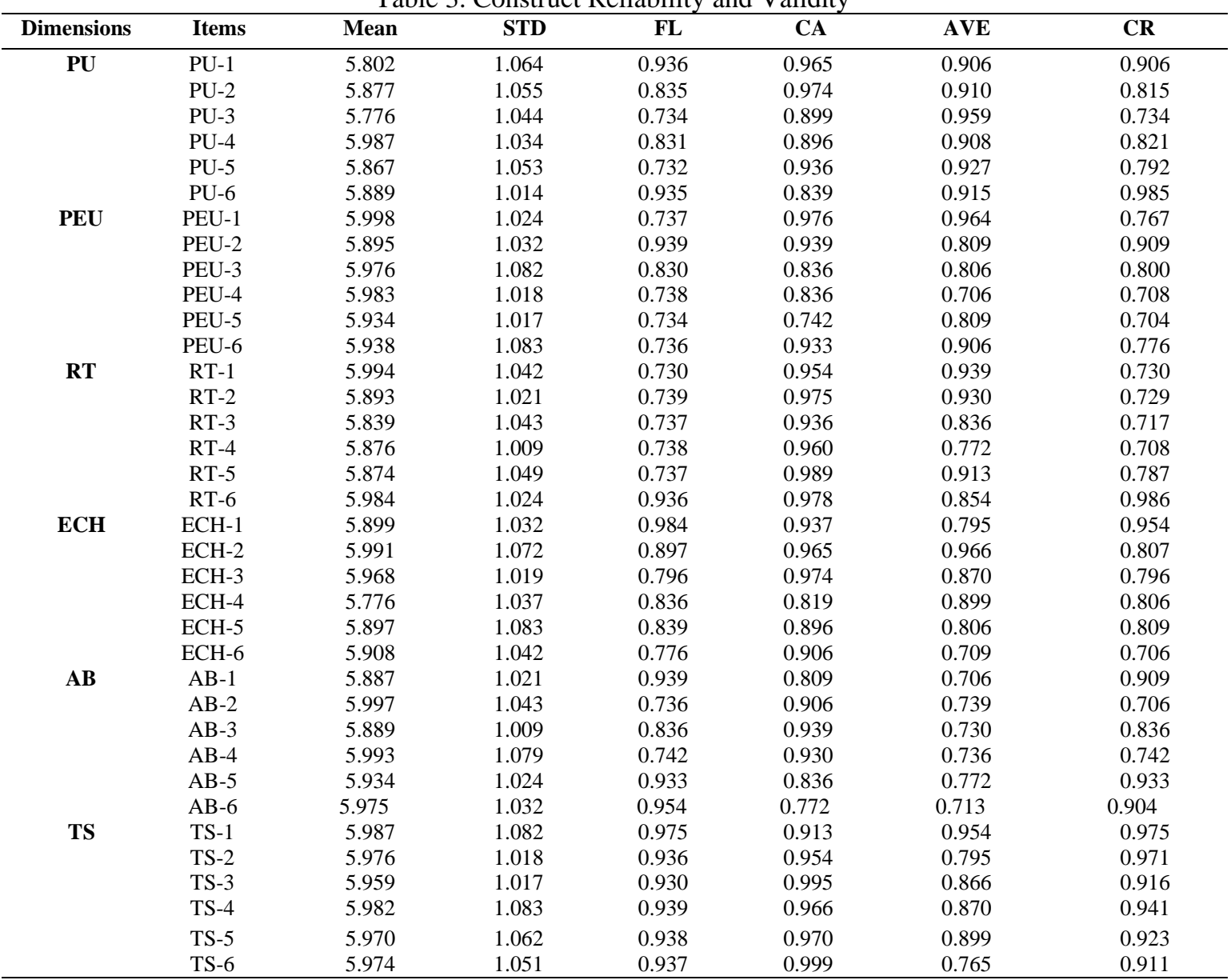

Note: $\mathrm{CA}=$ Cronbach's Alpha, $\mathrm{CR}=$ Composite Reliability, $\mathrm{FL}=$ Factor Loading 
As illustrated in figure 2, the average variance extracted (AVE) was measured for each model's item, the value of AVEs was more than 0.5, thus confirms that the measurement model had adequate convergent validity as recommended by [45]. Accordingly, the proposed model had satisfactory convergent validity. Subsequently, the discriminant validity test has conducted; the obtained findings indicated satisfactory discriminant validity of all the dimensions. As visualized in Table 4.

Table 4. The Discriminant validity for the Proposed Model

\begin{tabular}{ccccccc}
\hline Dimensions & PU & PEU & RT & ECH & AB & TS \\
\hline PU & $\mathbf{0 . 8 7 3}$ & & & & & \\
PEU & 0.674 & $\mathbf{0 . 9 7 8}$ & & & & \\
RT & 0.623 & 0.762 & $\mathbf{0 . 9 2 9}$ & & & \\
ECH & 0.548 & 0.698 & 0.764 & $\mathbf{0 . 8 1 7}$ & 0.911 & \\
AB & 0.651 & 0.712 & 0.672 & 0.677 & 0.774 & $\mathbf{0 . 9 1 6}$ \\
TS & 0.569 & 0.672 & 0.699 & 0.745 & \\
\hline
\end{tabular}

The two selected models have been separately tested using SEM. The obtained results visualize that both structural models afforded a good fit to the data. For the TAM model, the standardized path coefficients were calculated as shown in Figure 4.

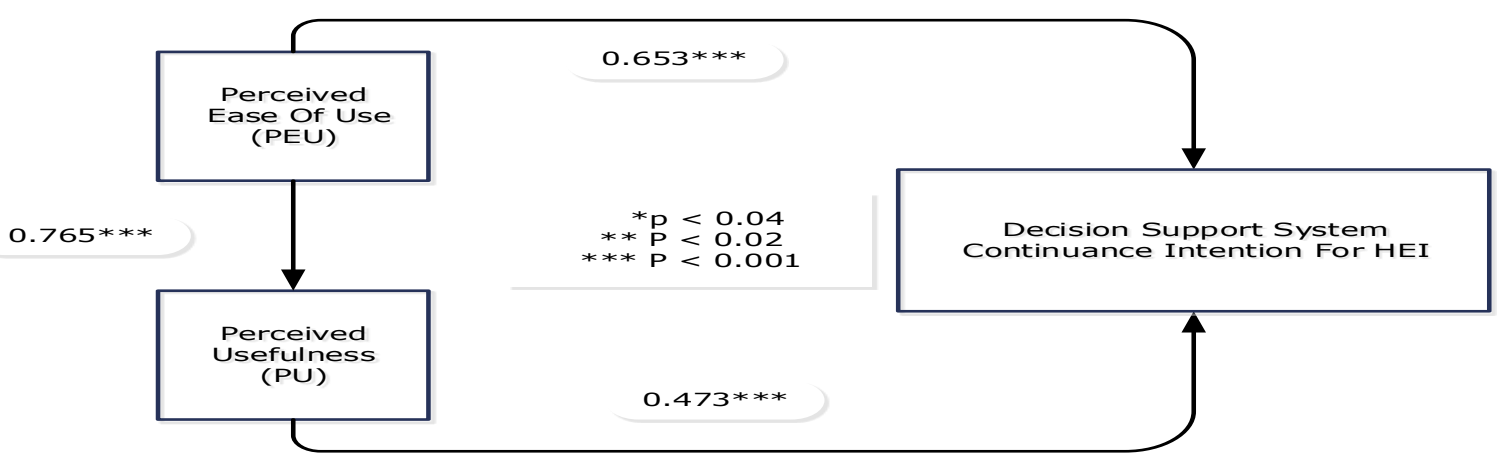

Figure 4. Standardized Path Coefficients of TAM

As indicated in Figure 4, all findings showed that PEU has a significant determinant of PU. PU and PEU have significant antecedents of a user's continuance intention to utilize DSS applications in HEI.

In the line with the above situation, the standardized path coefficients for the proposed model were calculated. All the paths between dimensions were significant as expected. The reasonable results on the interpretation of DSS continuance intent show the proposed model has a more conforming description. Overall, the proposed model has met all expectations and providing that a positive fit for the intended data as visualized in Figure 5.

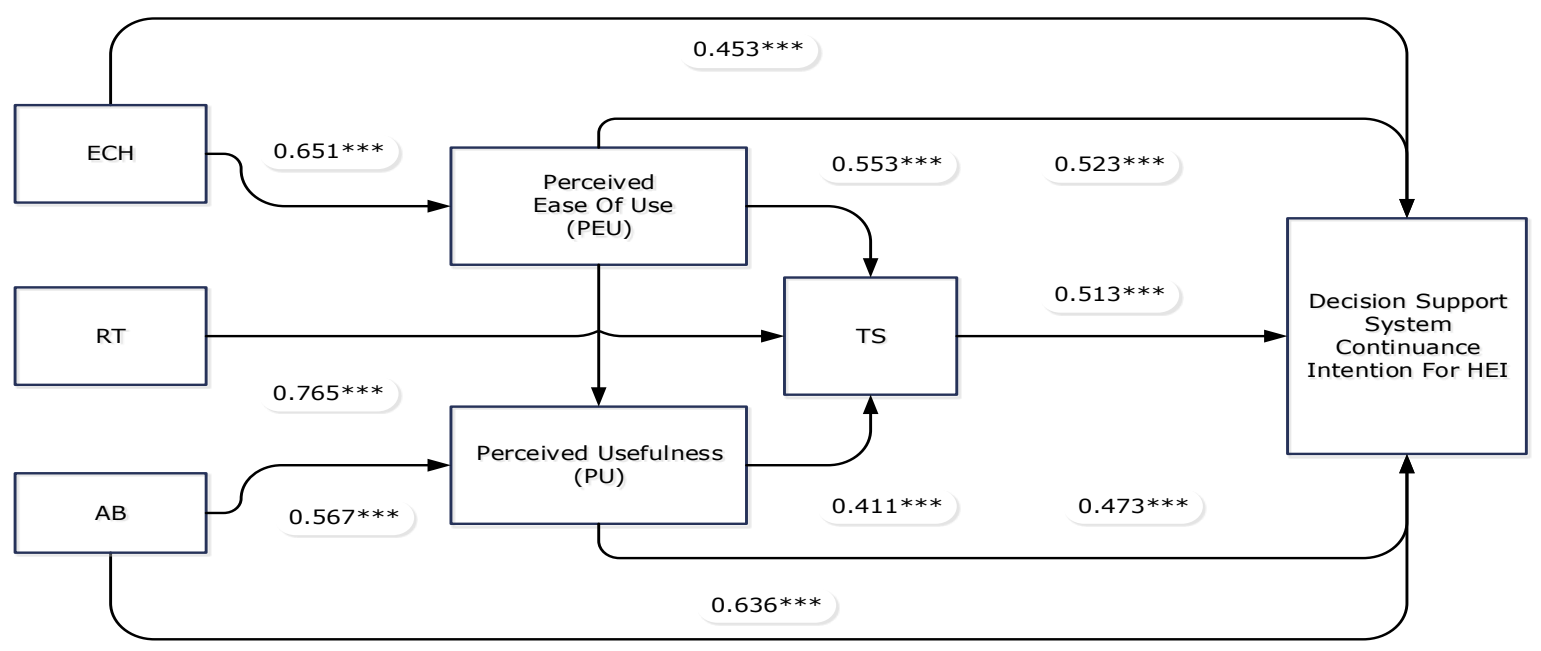

Figure 5. Standardized Path Coefficients of the Proposed Model 
As indicated from Figure 5, all the paths between dimensions were significant as expected. On the other hand, Table 5 demonstrates the result obtained from the one-way-ANOVA test among the years of experience of the participants and their impact on the continuance of the intention to using decision support systems in higher education institutes. in this test, the sample was classified based on the participants' experiences in using DSS. and then the descriptive statistic, p-value were calculated.

Table 5. One-way ANOVA test 1

\begin{tabular}{|c|c|c|c|c|}
\hline & The Years' Experience In Using DSS & No. of Participants & Mean & STD \\
\hline 1 & 15 Years and above & 40 & 4.7891 & 0.6621 \\
\hline 2 & $10 \ldots .14$ Years & 80 & 4.8661 & 0.6722 \\
\hline 3 & $5 \ldots 9$ Years & 70 & 4.4567 & 0.6323 \\
\hline \multirow[t]{3}{*}{4} & $<5$ Years & 50 & 4.5321 & 0.6724 \\
\hline & Total & 240 & & \\
\hline & p-value & & 0.9437 & \\
\hline
\end{tabular}

As indicated in Table 4, there is no impact between the participant's experiences and their intention to continuance using the DSS system. The p-value of 0.9437 is greater than the pretest level of significance (p $=0: 863>0: 05)$. Besides, another classification of samples was established for two types based on the type of DSS system they use. C-DSS comprehensive DSS system and P-DSS partial DSS system, and also calculated mean and STD deviation was conducted, and p-value was calculated. The obtained findings are demonstrated in Table 6.

Table 6. The Obtained Findings

\begin{tabular}{lllll}
\hline & DSS Type & No. of Participants & Mean & STD \\
\hline 1 & C-DSS comprehensive DSS system & 175 & 4.1421 & 0.6621 \\
2 & P-DSS partial DSS system & 65 & 4.9613 & 0.6722 \\
& Total & $\mathbf{2 4 0}$ & & \\
& p-value & $\mathbf{0 . 9 7 7 2}$ & \\
\hline
\end{tabular}

As demonstrated from Table 6, the result indicates that no impact between DSS type decision support system used (C-DSS, P-DSS) with intention continues using DSS system in higher education institutes. The $\mathrm{p}$-value of 0.9010 is greater than the pretest level of significance $(\mathrm{p}=0.9772>0: 05)$.

\section{RESULT OF HYPOTHESIS TESTING}

PU has a positive influence on DSS Continuance Intention (=0:641); therefore, hypothesis H1 is accepted. The influence of PEU on DSS Continuance Intention was found significant at $\mathrm{p}<0.5(=0: 172)$; therefore, H3 was accepted. A positive influence of PEU is observed on PU $(=0: 374)$; therefore, hypothesis $\mathrm{H} 2$ is accepted. PU has a significant positive impact on satisfaction with DSS $(=0.532)$; therefore, hypothesis $\mathrm{H} 4$ is accepted. PEU has a significant positive impact on satisfaction with DSS $(=0.549)$; therefore, hypothesis H5 is accepted. TS with DSS has a positive influence on the continued intention to use DSS $=(0.558)$; therefore, hypothesis H6 is accepted. ECH has a positive influence on their users' PU of DSS $=(0.511)$; therefore, hypothesis H7 is accepted. RT has a positive influence s positively related to their users' PU of DSS $=(0.641)$; therefore, hypothesis $\mathrm{H} 8$ is accepted. $\mathrm{AB}$ has a positive influence on their PEU of DSS $=(0.523)$; therefore, hypothesis H8 is accepted. RT has a positive influence on their satisfaction with DSS $=(0.629)$; therefore, hypothesis $\mathrm{H} 8$ is accepted.

\section{DISCUSSION}

This paper focus investigates understanding the DSS continuance intention by proposing a model and its influencing factors to expose the relationship between those factors. The evidence is collected in this research indicates that both selected models are familiars and acceptable to fit the data levels. The proposed model can confirm the best interpretive level as compared with TAM and TOE. Besides, the proposed model contributes to delivering relevant information for comprehension of the behavior of interest.

On the other aspect and in line with the existing literature, providing real-time decision support would have a significant direct impact on the intention of the system to continue to utilize. Since DSS systems are becoming inevitable and more powerful, stakeholders may become increasingly demand in applying them. In this case, stakeholders simply need more and more demand for real-time decision support systems. Therefore, DSS users place a high weight on real-time decision support.

\section{THE IMPLICATIONS OF THIS STUDY}

The obtained findings in the context of this study have several implications for relevant research. Since the limitations of the current studies examine determents that influence users' intention to continue using 
DSS systems during and after having them. this study proposed model to adopt several elements from two familiar models (TAM and TOE) for measuring stakeholders' behaviors during and after utilize them DSS systems. The obtained results by using the SEM analysis show that the proposed model fits the data and had a good explanation than the existing models.

On the other hand, the results show the importance of equipping DSS with real-time support because they have positive repercussions in the decision-making process, and there will be two directions for this stimulus, the first direction is for stakeholders to continue to use these systems or the need to acquire them. On the other hand, motivating DSS developers to develop smart systems that support real-time, as well as emphasizing the need for these systems to behave in a satisfactory way to users in terms of ease of use and adoption. On the same aspect, since this study was focused on DSS as software systems, it can the obtained results may be extended to other software systems.

The core differences between our study and other relevant studies are summarized as follows.

1) In this study, two well-known models (TOE and TAM) are adopted to produce the research model (see figure 3). While the other studies adopt either TOE or TAM. 2) The selected sample was from actual users to make the research and conclusions realistic. 3) The evaluation process for the decision support systems programs selected in this study was carried out on real systems used within the institutions. 4) Initiating the election of another group of other HEIs to expand the scope of this study in future work to include all institutions in HEIs.

\section{CONCLUSION}

DSSs have become very necessary in the management of institutions because of the support they provide to make the best decisions, especially in HEIs sector.Almost all higher education institutions now have their own DSSs. These systems are sometimes similar in some tasks and sometimes differ according to the nature of the institution. Continuing the use of these systems by institutions. Failure to continue is one of the important issues that need to be investigated. Measuring the extent of continuity using decision support systems is an urgent necessity.

This paper discussed to what extent these institutions have the intention to continue to adopt decision support systems. Besides, This paper contributed to the development of a model in this context and gave some hypotheses that have been verified that the decision support systems used are a pure necessity and must be continued. In addition, this paper recommended other institutions that do not have decision support systems to adapt as soon as possible so that they can keep pace with development and take appropriate decisions.

\section{LIMITATIONS}

In the context of this study, several limitations existed. Firstly, this study was conducted on three HEIs only, in this case, it lacks the characteristic of generality; therefore, the authors strongly recommend that all institutions of higher education be included as future work, to obtain satisfactory and applicable results. Secondly, this study was carried out on the Higher education sector and the obtained findings might not suitable for other sectors unless the stakeholders of these sectors are involved in the data collection process.

\section{REFERENCES}

[1] T. Mettler and V. Vimarlund, "Understanding business intelligence in the context of healthcare," Health informatics journal, vol. 15, pp. 254-264, 2009.

[2] C. Giannoulis and A. Ishizaka, "A Web-based decision support system with ELECTRE III for a personalised ranking of British universities," Decision Support Systems, vol. 48, pp. 488-497, 2010.

[3] E. Sugiyarti, K. A. Jasmi, B. Basiron, M. Huda, K. Shankar, and A. Maseleno, "Decision support system of scholarship grantee selection using data mining," International Journal of Pure and Applied Mathematics, vol. 119, pp. 2239-2249, 2018.

[4] S. B. Kotsiantis, "Use of machine learning techniques for educational proposes: a decision support system for forecasting students' grades," Artificial Intelligence Review, vol. 37, pp. 331-344, 2012.

[5] H. Holden and R. Rada, "Understanding the influence of perceived usability and technology self-efficacy on teachers' technology acceptance," Journal of Research on Technology in Education, vol. 43, pp. 343-367, 2011.

[6] F. D. Davis, "Perceived usefulness, perceived ease of use, and user acceptance of information technology," MIS quarterly, pp. 319-340, 1989.

[7] J. Baker, "The technology-organization-environment framework," in Information systems theory, ed: Springer, 2012, pp. 231-245.

[8] Z. Dulcic, D. Pavlic, and I. Silic, "Evaluating the intended use of Decision Support System (DSS) by applying Technology Acceptance Model (TAM) in business organizations in Croatia," Procedia-Social and Behavioral Sciences, vol. 58, pp. 1565-1575, 2012.

[9] P. J. Hu, P. Y. Chau, O. R. L. Sheng, and K. Y. Tam, "Examining the technology acceptance model using physician acceptance of telemedicine technology," Journal of management information systems, vol. 16, pp. 91-112, 1999. 
[10] F. Portela, J. Aguiar, M. F. Santos, Á. Silva, and F. Rua, "Pervasive intelligent decision support system-technology acceptance in intensive care units," in Advances in Information Systems and Technologies, ed: Springer, 2013, pp. 279-292.

[11] R. Angeles, "Using the Technology-Organization-Environment Framework for Analyzing Nike's Considered Index Green Initiative, a Decision Support System-Driven System," J. Mgmt. \& Sustainability, vol. 4, p. 96, 2014.

[12] M.-J. Pan and W.-Y. Jang, "Determinants of the adoption of enterprise resource planning within the technologyorganization-environment framework: Taiwan's communications industry," Journal of Computer information systems, vol. 48, pp. 94-102, 2008.

[13] H. O. Awa, O. U. Ojiabo, and L. E. Orokor, "Integrated technology-organization-environment (TOE) taxonomies for technology adoption," Journal of Enterprise Information Management, 2017.

[14] S. H. M. Ayad Hameed Mousa, Sundus Hameed Mousa, and Hazim Allawi Obaid, "Advance Acceptance Status Model for E-learning Based University's Academics and Students," Journal of Material Sciences and Engineering: IOP, p. 12, 20202020.

[15] A. H. Mousa, "Data virtualization design model for near real time decision making in business intelligence environment," PhD Thesis, College of Art and Science, Universiti Utara Malaysia, 2017.

[16] A. H. Mousa, Z. N. Aldeen, I. S. Nasir, and R. S. Hamdi, "Measuring Readiness Of Higher Education Institutes Towards Adopting E-Learning Using The Technology Acceptance Model," context, vol. 4, p. 10.

[17] N. Marangunić and A. Granić, "Technology acceptance model: a literature review from 1986 to 2013," Universal access in the information society, vol. 14, pp. 81-95, 2015.

[18] L. G. Tornatzky, M. Fleischer, and A. K. Chakrabarti, Processes of technological innovation: Lexington books, 1990.

[19] S. B. Wicker, Error control systems for digital communication and storage vol. 1: Prentice hall Englewood Cliffs, 1995.

[20] A. H. Mousa, H. A. Raheem, and N. Mohammed, "An Evaluation Instrument (QU) for Measuring the usability of Business Intelligence Application," International Journal of Engineering \& Technology, vol. 8, pp. 456-460, 2019.

[21] S. Hong, J. Y. Thong, and K. Y. Tam, "Understanding continued information technology usage behavior: A comparison of three models in the context of mobile internet," Decision support systems, vol. 42, pp. 1819-1834, 2006.

[22] C. Liao, J.-L. Chen, and D. C. Yen, "Theory of planning behavior (TPB) and customer satisfaction in the continued use of e-service: An integrated model," Computers in human behavior, vol. 23, pp. 2804-2822, 2007.

[23] Y. Sun and S. Mouakket, "Assessing the impact of enterprise systems technological characteristics on user continuance behavior: An empirical study in China," Computers in Industry, vol. 70, pp. 153-167, 2015.

[24] Z. Dörnyei and T. Taguchi, Questionnaires in second language research: Construction, administration, and processing: Routledge, 2009.

[25] E. Van Teijlingen and V. Hundley, "The importance of pilot studies," Nursing Standard (through 2013), vol. 16, p. 33, 2002.

[26] O. Doody and C. M. Doody, "Conducting a pilot study: Case study of a novice researcher," British Journal of Nursing, vol. 24, pp. 1074-1078, 2015.

[27] U. Sekaran and R. Bougie, Research methods for business: A skill building approach: John Wiley \& Sons, 2016.

[28] P. Ghauri, K. Grønhaug, and R. Strange, Research methods in business studies: Cambridge University Press, 2020.

[29] H. O. Awa, O. U. Ojiabo, and B. C. Emecheta, "Integrating TAM, TPB and TOE frameworks and expanding their characteristic constructs for e-commerce adoption by SMEs," Journal of Science \& Technology Policy Management, vol. 6, pp. 76-94, 2015.

[30] R. Cakır and E. Solak, "Attitude of Turkish EFL learners towards e-Learning through Tam Model," Procedia-Social and Behavioral Sciences, vol. 176, pp. 596-601, 2015.

[31] D. Persico, S. Manca, and F. Pozzi, "Adapting the Technology Acceptance Model to evaluate the innovative potential of e-learning systems," Computers in Human Behavior, vol. 30, pp. 614-622, 2014.

[32] T.-L. Huang and S. Liao, "A model of acceptance of augmented-reality interactive technology: the moderating role of cognitive innovativeness," Electronic Commerce Research, vol. 15, pp. 269-295, 2015.

[33] R. T. Frambach and N. Schillewaert, "Organizational innovation adoption: A multi-level framework of determinants and opportunities for future research," Journal of business research, vol. 55, pp. 163-176, 2002.

[34] Y. Hwang, "Investigating enterprise systems adoption: uncertainty avoidance, intrinsic motivation, and the technology acceptance model," European journal of information systems, vol. 14, pp. 150-161, 2005.

[35] L. G. Wallace and S. D. Sheetz, "The adoption of software measures: A technology acceptance model (TAM) perspective," Information \& Management, vol. 51, pp. 249-259, 2014.

[36] A. H. Mousa, H. A. Raheem, and N. Mohammed, "An Evaluation Instrument (QU) for Measuring the usability of Business Intelligence Application," International Journal of Engineering \& Technology, vol. 7, pp. 849-852, 2018.

[37] H. Son, Y. Park, C. Kim, and J.-S. Chou, "Toward an understanding of construction professionals' acceptance of mobile computing devices in South Korea: An extension of the technology acceptance model," Automation in construction, vol. 28, pp. 82-90, 2012.

[38] Q. Jia, Y. Guo, and S. J. Barnes, "Enterprise 2.0 post-adoption: Extending the information system continuance model based on the technology-Organization-environment framework," Computers in Human Behavior, vol. 67, pp. 95-105, 2017.

[39] J. S. Armstrong and T. S. Overton, "Estimating nonresponse bias in mail surveys," Journal of marketing research, vol. 14, pp. 396-402, 1977 
[40] D. M. Lambert and T. C. Harrington, "Measuring nonresponse bias in customer service mail surveys," Journal of Business Logistics, vol. 11, pp. 5-25, 1990.

[41] J. C. Anderson and D. W. Gerbing, "Structural equation modeling in practice: A review and recommended two-step approach," Psychological bulletin, vol. 103, p. 411, 1988.

[42] J. F. Hair, W. C. Black, B. J. Babin, R. E. Anderson, and R. L. Tatham, Multivariate data analysis vol. 5: Prentice hall Upper Saddle River, NJ, 1998.

[43] W. W. Chin, A. Gopal, and W. D. Salisbury, "Advancing the theory of adaptive structuration: The development of a scale to measure faithfulness of appropriation," Information systems research, vol. 8, pp. 342-367, 1997.

[44] J. F. Hair, W. C. Black, B. J. Babin, R. E. Anderson, and R. L. Tatham, "Multivariate data analysis (Vol. 6)," ed: Upper Saddle River, NJ: Pearson Prentice Hall, 2006.

[45] C. Fornell and D. F. Larcker, "Evaluating structural equation models with unobservable variables and measurement error," Journal of marketing research, vol. 18, pp. 39-50, 1981

\section{BIOGRAPHY OF AUTHORS}

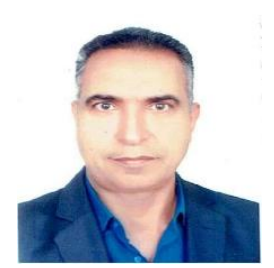

Ali Hussein Mohammed:

He received his B.Sc. degree in Mathematics and Computer from the faculty of education, University of Mosul, Iraq in 1990. Then he earned M.Sc. and Ph.D. degrees from Alexandria University- Egypt in 2013 and 2016. His research and professional interests include image processing, optimization techniques, security technologies, and machine learning.

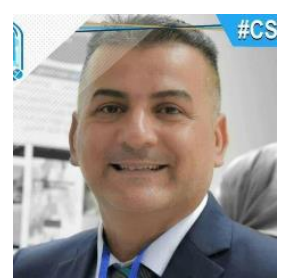

\section{Ayad Hameed Mousa:}

Ayad Hameed Mousa was born in Basrah, Iraq, He received his Ph.D. in computer science in 2017, is an assistant professor at the College of Computer Science and Information Technology, University of Kerbala, department of computer science. His research is situated in the field of Technology \& Innovation, with a special focus on Software engineering, business intelligence modeling, data mining, data warehouse, and e-learning modeling. He is actively engaged in several scientific projects (bilateral cooperation, national projects). A university lecturer from 2005 and ongoing. He is the author or co-author of more than 27 papers in international journals and international conference contributions.

\section{Nawal Mousa Almeyali,}

BA in Electrical Engineering, Al-Mustansiriya University, Higher diploma in Computers University of Technology, Master of Industrial Management, University of Tehran. Skill highlights:.Project management, Maintenance of medical devices and computers, and Rehabilitation of buildings and control systems

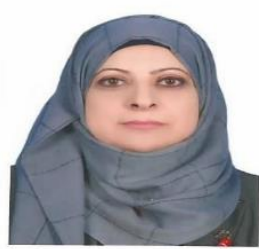

Intedhar Shakir Nasir received BSc in Statistics, Baghdad University, College of Administration and Economics, Baghdad, Iraq in 1990. Then she earned High Diploma in Computer Qualification from Iraqi Commission for Computer and Informatics- Institute of Postgraduate studies in Informatics, Baghdad, Iraq, in 2003. Later she graduated her M.Sc. in Computer Science from DR. Babasaheb Ambedkar Marthwada University Aurangabad. Maharashtra (India), 2010.She is currently working as lecturer at the Department of Family and Community Medicine, College of Medicine, University of Kerbala 